\title{
Design of Autonomous Learning Courseware
}

\author{
Chao Lv \\ Computer Information Center, Beijing Institute of Fashion Technology, Beijing, 100029, China \\ Icrabbit@163.com
}

Keywords: Autonomous learning; Courseware; Design; Characteristics; Module

\begin{abstract}
It is very important to establish the dominant position of students in learning in education informatization era. Namely, students should be regarded as center and orientation during learning. In the paper, deficiency of traditional learning mode is proposed on the basis of analyzing autonomous learning. Characteristics and structure of autonomous learning courseware are proposed. Teaching design of autonomous learning courseware is discussed.
\end{abstract}

\section{Autonomous Learning}

Autonomous learning can reflect the students' subject status fully, and students' learning initiative can be exerted, and more targeted learning can be achieved. Therefore, the learning mode is advocated by education experts.

Autonomous learning refers to a learning activity that learners apply certain media for active, positive and transcendence learning under guidance or information disclosure of relevant personnel. In the teaching activity, students can construct knowledge, and comprehensively improve formation skills, development ability and quality, which mainly depends on students' autonomous learning degree.

Autonomous learning include independent determination of learning objectives, autonomous formation of learning plan, autonomous selection of learning materials, autonomous selection of learning methods, autonomous determination of learning progress, autonomous testing and evaluation of learning results, autonomous defect compensation and correction, etc [1].

\section{Characteristics of Autonomous Learning}

Initiative. Autonomous learning is personalized learning form. Learners can actively determine learning objectives, learning content, learning time and place. Learning activities are caused by learners themselves. Completion of learning tasks mainly depends on self-consciousness and initiative property of learners.

Independence. It is required in autonomous learning that learners don't depend on teachers and others to carry out study activities alone without pressure and request from the outside world as well as direct social supervision. Learning success depends on own initiative exploration and active self-monitoring.

Open. The whole process of autonomous learning is open: the learning process can be arbitrarily accelerated and decelerated; Data query can be arbitrarily jumped, learners can arbitrarily obtain other information with nothing to do with learning, therefore there is no fixed path in learning [2].

Because the autonomous learning has initiative, independent and open characteristics, they can adjust the learning process according to own characteristics and need as long as learners want to learn. Therefore, learning can be more targeted with opener thinking, wider free innovation space and better effect.

\section{Problems in Traditional Learning Mode}

Traditional learning refers that students accept learning passively. Traditional learning has the core of 'learning'. It emphasizes the knowledge transfer, including concept, theory, method, etc. which are 
passed on from one person to another. In the education process from elementary school to junior middle school, senior middle school and even university, one teacher teaches on the podium, students record notes, review and take part in exams constantly. It is typical traditional learning mode. Students can obtain concept, theory and method through 'teaching' by teachers and 'learning' by students.

Emphasis on Interpretation of Teaching Content, and Ignorance of Guidance of Students' Learning Methods. Exhibition of teaching content is more emphasized in traditional teaching mode. Some teachers pay attention to participation of students. However, teachers notice how to assist students to solve difficulties which are not related to knowledge, such as memory difficulties, low reading ability, low practical operation level, low correctness of reading answers, etc [3].

Students' Individual Differences Are Ignored in the Aspect of Teaching Content. The Individual difference problems caused by inconsistent learning abilities and inconsistent learning starting points of students cannot be solved by traditional teaching mode. If knowledge is taught according to the same teaching content and the same teaching method, students with quick learning speed cannot obtain 'sufficient knowledge', students with slow learning speed cannot keep up with the pace.

Deficient Interactivity in Traditional Teaching Mode. Student's commonness is emphasized in traditional teaching mode, while cultivation of students' personality is ignored. In the classroom, teachers spread knowledge in an inculcated mode, and mechanically demand students to master. It is lack of interaction and scene display [4].

\section{Characteristics of Autonomous Learning Courseware}

Media Integration. Although guidance of teachers is available in autonomous learning, students adopt self-study mode under most circumstances. The biggest difficulty in autonomous learning lies in understanding of new knowledge. Text element expression information is not intuitive, thereby affecting understanding and mastering of students to new knowledge to a large extent. Graph, text, sound, image and other media elements are used for expressing knowledge, thereby achieving vivid and lifelike teaching information. The highly expressive media information has stronger attraction to students, which is beneficial for students to understand and master new knowledge rapidly [5].

Operation Interactivity. Teaching information on autonomous learning courseware can be shown in the form of hypertext and hypermedia. Learners can actively participate in the learning process through man-machine interactive dialogue. Learners can freely select learning contents according to own demand, they also can adjust the learning process automatically, thereby realizing autonomous learning through flexible practice and friendly performance evaluation.

Structure Nonlinear Feature. Nonlinear feature of autonomous learning courseware is developed under the support of hypertext and hypermedia technology. The structure combination is variable. Learners can determine learning path independently.

\section{Teaching Design of Autonomous Learning Courseware}

Teaching design mainly refer that systematic and scientific viewpoint and method are applied for selecting and designing six basic elements rationally according to teaching objectives and features of teaching objects: learning content, extension of learning resources, teaching strategies, motivation strategy, learning guidance and learning evaluation. They are organically combined in the system for forming optimized teaching system structure. Teaching design mode of autonomous learning courseware is shown in Fig. 1.

Making Clear Teaching Goal. Teaching goal has the vital significance in the courseware design. Teaching goal is the starting point and foundation of courseware design. Courseware teaching contents and teaching process are mainly determined by teaching goal. Completion of courseware production is also measured according to the degree of reaching teaching goal. 
Analyzing Learning Objects. Learners' learning features include learner's cognitive stage, cognitive pattern, cognitive level, etc. Concern on learning topic, learning experience and life experience of learners also should be analyzed in order to realize effective design of the courseware [5].

Learning Content Design. Learning content refers to course contents that must be mastered by students. Learning content design mainly include learning content selection and organization.

Teaching Strategy Design. Teaching strategy in autonomous learning courseware refers that the adopted methods and selected media have been determined, which cannot be randomly changed. Teaching strategy has the function of showing the learning content to students in a mode which can be easily learned, thereby assisting them to understand and master and achieving learning goals [6].

Motivation Strategy Design. Teaching strategy affects student's cognition, and motivation strategy affects students' emotion and attitude, both are equally important.

Learning Guidance Design. Learning guidance refers that various guidance and assistance are provided in order to assist students to complete autonomous learning. Learning guidance design includes learning objectives, learning methods and learning path [7].

Learning Evaluation Design. Learning evaluation refers to judgment on learning process and learning results. Autonomous learning courseware should be based on self-test and formative assessment, namely evaluation subject is student himself. Evaluation aims at assisting students to adjust and improve learning [8,9].

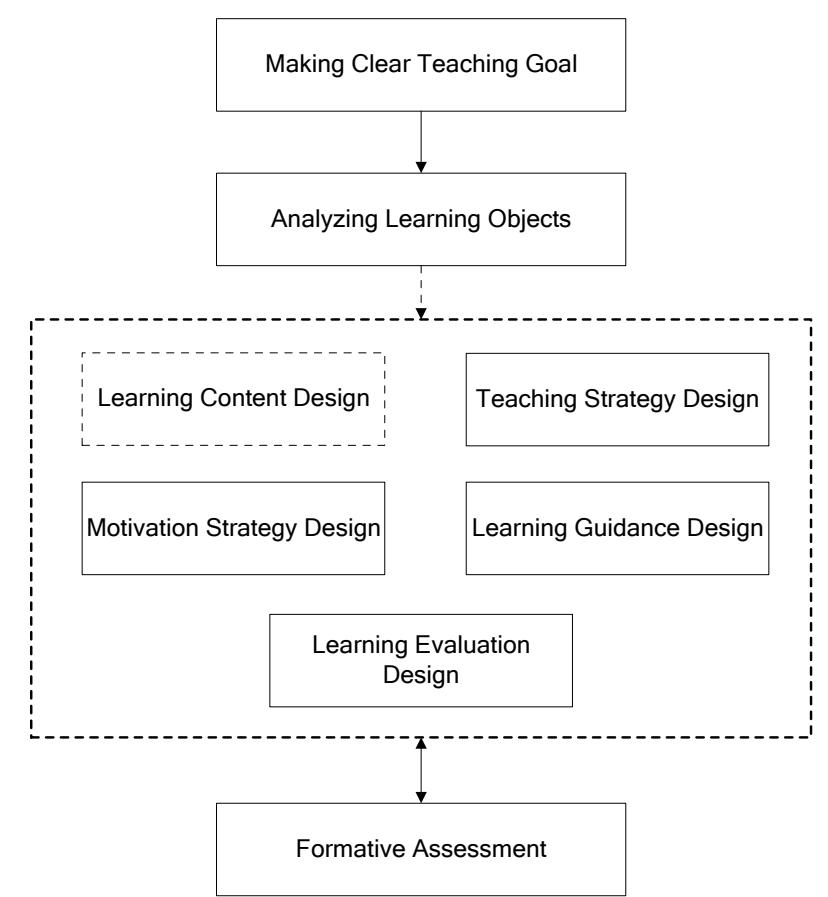

Figure 1. Teaching design mode of autonomous learning courseware

\section{Composition of Autonomous Learning Courseware (Fig. 2)}

Teaching Module. In the paper, discipline curriculum is mainly introduced to learners. Knowledge reserve for learning the course, learning goals and knowledge structure of discipline that can be reached through learning are described.

Teaching Resource Database. Resource database contents should include complete knowledge content, including courseware, sample, data, resource sharing, software sharing, etc [10].

Student Module. The module is used for recording each student's learning process, including name, class, learning status quo, vulnerabilities, and so on, and they can be dynamically tracked and fed back. 
Test Mode. The module is used for storing sample database designed according to teaching goal, thereby facilitating student exercise and self-test [11].

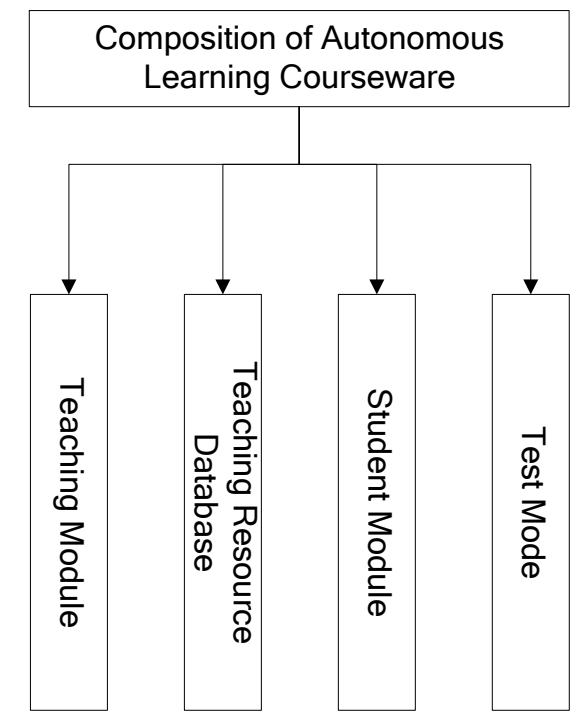

Figure 2. Composition of autonomous learning courseware

\section{Acknowledgements}

The paper is supported by 2015 teaching and education reform project of Beijing Institute of Fashion Technology 'Autonomous Learning Courseware Design and Realization with Excel as an Example' (JG - 1531).

\section{References}

[1] X.Y.Wang, X.X.Qiao, Study on the autonomous learning Courseware Designed and Exploited by Agricultural University, Journal of Anhui Agri. Sci, Vol.37(2009)NO.28, pp13925-13926.

[2] G.Luo, Q.Z.Zhang, On the Motivation and strategy of Web autonomous learning Courseware, China Educational Technology, 2002 NO.189, pp 51-54.

[3] N.J.Lu, Properly Preparing English Courseware - Helping Students autonomous learning, Education and Vocation, 2004 NO.21, pp 46-47.

[4] S.Liang, K.F.Wang and H.Q.Wang, The Innovative Design of Teaching Strategies in Higher Vocational Colleges - Exploration of " Autonomous Learning Multimedia Courseware", Chinese Vocational and Technical Education, 2006 NO.248, pp 34-36.

[5] W.Z.Cao, The Design of Network Courseware in autonomous learning Mode, Modern Distance Education, 2001 NO.79, pp 57-60.

[6] Y.Huang, Design of Online Courseware for Autonomous Learning, Modern Educational Technology, Vol.18 (2008) NO.10, pp80-84.

[7] Y.Yang, On the Design of Computer Courseware Supporting autonomous learning - A Case Study of Homecoming, Language Planning, 2002 NO.8, pp 44-45.

[8] H.B.Wang, Y.L.Guo, Theory and Practice of Developing Autonomous Foreign Language Learning Network-based Courseware, Modern Educational Technology, Vol.17 (2007) NO.7, pp65-68. 
[9] Z.B.Xie, On the Development of Autonomous Learning Courseware, Computer Knowledge and Technology, Vol.9 (2013) NO.2, pp339-340.

[10] W.Shi, Z.H.Wang and H.M.Cui, The Design of CAI Teaching Courseware Based on Autonomous Learning Model, Time Education, (2016)NO.8, pp181.

[11]C.J.Song, X.J.Chen, Research and Development of the Self-learning Courseware, Electronic Design Engineering, Vol.19 (2011) NO.19, pp49-51. 